\title{
Morphological and genetic identification of Anisakis paggiae (Nematoda: Anisakidae) in dwarf sperm whale Kogia sima from Brazilian waters
}

\author{
Maria Isabel N. Di Azevedo', Marcelo Knoff ${ }^{2}$, Vitor L. Carvalho ${ }^{3}$, \\ Wildon N. Mello ${ }^{4,5}$, Eduardo J. Lopes Torres ${ }^{4,5}$, Delir C. Gomes ${ }^{2}$, Alena M. Iñiguez ${ }^{1, *}$ \\ ${ }^{1}$ LABTRIP, Instituto Oswaldo Cruz, Fiocruz, Rio de Janeiro, 21045-900 RJ, Brazil \\ ${ }^{2}$ Laboratório de Helmintos Parasitos de Vertebrados, Instituto Oswaldo Cruz, Fiocruz, Rio de Janeiro, 21045-900 RJ, Brazil \\ ${ }^{3}$ Associação de Pesquisa e Preservação de Ecossistemas Aquáticos-AQUASIS, Caucaia, 61627-010 CE, Brazil \\ ${ }^{4}$ Laboratório de Helmintologia Roberto Lascasas Porto, Faculdade de Ciências Médicas, UERJ, Rio de Janeiro, 20511-070 RJ, \\ Brazil \\ ${ }^{5}$ Laboratório de Ultraestrutura Celular Hertha Meyer, Instituto de Biofísica Carlos Chagas Filho and Instituto Nacional \\ de Ciência e Tecnologia em Biologia Estrutural e Bioimagens, UFRJ, Rio de Janeiro, 21941-902 RJ, Brazil
}

\begin{abstract}
Anisakid nematodes have been identified in a wide variety of fish and marine mammal species. In Brazil, Anisakis physeteris, A. insignis, A. typica, A. nascetti, and those of the A. simplex complex have been reported infecting fishes and cetaceans. In this study, specimens collected from a dwarf sperm whale Kogia sima (Owen, 1866) stranded on the northeastern coast of Brazil were identified through morphological and genetic analyses as A. paggiae. Anisakids were examined through differential interference contrast light and scanning electron microscopy (SEM). Morphological and morphometric analysis revealed that these specimens belonged to Anisakis sp. clade II and more specifically to A. paggiae, exhibiting a violin-shaped ventriculus and 3 denticulate caudal plates, which are taxonomic characters considered unique to this species. Genetic analysis based on the mtDNA cox2 gene confirmed our identification of A. paggiae. Phylogenetic trees using both maximum likelihood and neighbor-joining methods revealed a strongly supported monophyletic clade (bootstrap support $=100 \%$ ) with all available A. paggiae sequences. Integrative taxonomic analysis allowed the identification of $A$. paggiae for the first time in Brazilian waters, providing new data about their geographical distribution. Moreover, here we present the first SEM images of this species.
\end{abstract}

KEY WORDS: Cetacean · Parasitic nematode $\cdot$ Scanning electron microscopy $\cdot$ Light microscopy mtDNA cox $2 \cdot$ Brazil

Resale or republication not permitted without written consent of the publisher

\section{INTRODUCTION}

Nematodes of the genus Anisakis Dujardin, 1845 are common parasites of marine mammals, the definitive hosts. Humans can become infected by ingesting raw or undercooked fish, the intermediate hosts, thereby acquiring anisakiasis (Mattiucci \& Nascetti 2008). In Brazil, anisakid infections reported in the marine cetaceans Stenella clymene, S. longirostris,
Peponocephala electra, Steno bredanensis, and Kogia breviceps (Motta et al. 2008) were identified as A. typica (Iñiguez et al. 2011). Anisakis typica and $A$. physeteris were previously identified in Brazil by means of genetic markers (D'Amelio et al. 2000, Mattiucci et al. 2002, Mattiucci \& Nascetti 2008, Iñiguez et al. 2009, 2011, Borges et al. 2012). Recently, A. nascettii was identified and genetically characterized in a Gervais' beaked whale Mesoplodon europaeus 
stranded on the northeast coast of Brazil (Di Azevedo et al. 2014). Anisakis nascettii, A. physeteris, A. insignis, A. typica, and those of the A. simplex complex were therefore the only species identified to date in cetaceans from this country (Luque et al. 2010, Di Azevedo et al. 2014). However, some specimens were reported as Anisakis sp. (Carvalho et al. 2010, Luque et al. 2010), suggesting that other species might also be found in the littoral of Brazil.

Anisakis paggiae Mattiucci et al. 2005 was described as a taxon of Anisakis sp. clade II in $K$. sima and $K$. breviceps from West Atlantic waters, on the coast of Florida, USA (Mattiucci et al. 2005). Anisakis paggiae have also been reported on the coast of Europe (Mattiucci et al. 2007), Caribbean Sea (Colón-Llavina et al. 2009), Gulf of Mexico (Cavallero et al. 2011), coast of Japan (Murata et al. 2011), and in the Irminger Sea, North Atlantic Ocean (Klimpel et al. 2011). Reports of A. paggiae in swordfishes from Atlantic tropical-equatorial waters (Garcia et al. 2008, 2011) expanded the geographical distribution of this species to South Atlantic waters $\left(10^{\circ} \mathrm{S}\right)$. Recently, Anisakis sp. specimens genetically close to $A$. paggiae were identified in a dwarf sperm whale $K$. sima from the Philippine archipelago (Quiazon et al. 2013). In the present study, integrative taxonomy, based on genetic and morphological data, revealed for the first time the presence of $A$. paggiae on the northeast coast of Brazil, providing a new geographical location for this species.

\section{MATERIALS AND METHODS}

\section{Samples and morphological analysis}

Nematodes were recovered during necropsy of a dwarf sperm whale stranded on Barra das Moitas beach, Amontada municipality in the state of Ceará, northeastern Brazil (030 01' 07" S, 39 39' 46" W), on 2 August 2012. Worms (2 males and 3 females) were collected from stomach contents and conserved in ethanol $(70 \%)$ until morphological screening. First, all specimens were observed through light microscopy to identify taxonomic characters of genus and species, following Davey (1971) and Mattiucci et al. (2005). Then, 1 male and 3 females had their anterior and posterior regions separated, clarified by Amann's lactophenol, and analyzed with a Zeiss Axiophot microscope, using bright field and differential interference contrast. Mid-section fragments were freezedried for molecular studies. One male was reserved for scanning electron microscopy (SEM) following the protocol of Lopes Torres et al. (2013). Two specimens of Anisakis paggiae including 1 male (no. 35796a) and 1 female (no. 35796b) were deposited in the Helminthological Collection of Oswaldo Cruz Institute (Coleção Helmintologica do Instituto Oswaldo Cruz-CHIOC), Oswaldo Cruz Foundation (Fiocruz), Rio de Janeiro.

\section{DNA extraction and PCR assay}

Samples were ground in liquid nitrogen and DNA extraction was conducted using the QIAamp® DNA Mini Kit (Qiagen), as described by Iñiguez et al. (2012). DNA was quantified using a spectrophotometer (Gene Quant II, Pharmacia Biotech). A mitochondrial DNA fragment of $629 \mathrm{bp}$ from cytochrome oxidase gene subunit 2 (mtDNA cox2) was amplified using primers and PCR conditions described by Nadler \& Hudspeth (2000) and Knoff et al. (2012), respectively. Amplicons were directly sequenced using the Big Dye Terminator v 3.1 Cycle Sequencing Ready Reaction kit (Applied Biosystems) in a 3100 Automated DNA Sequencer as recommended by the suppliers.

\section{Sequencing analysis}

Sequences were analyzed using the global Basic Local Alignment Search Tool (BLAST, National Center for Biotechnology Information database) and BioEdit v7.0.4.1 (Department of Microbiology, North Carolina State University, USA). Intra- and inter-specific genetic distances were calculated using MEGA v 6 (Tamura et al. 2013) with the Kimura-2-parameter (K2P) model (Kimura 1980). Maximum likelihood (ML) and neighbor-joining (NJ) phylogenetic trees were inferred using the same software, with the K2P model following the Barcoding CBOL protocol (www. barcodeoflife.ord/content/resources/standards-andguidelines), and a general time reversible (GTR) model, as selected by the Model Selection tool in MEGA, respectively. Complete deletion and gamma distribution parameters were used. One thousand bootstrap replicates were applied to evaluate the reliability of clusters. Hysterothylacium aduncum (GenBank JQ934891) was used as the outgroup. The cox2 gene alignment was examined for genetic signatures (i.e. polymorphisms shared only by individuals of a species or a clade), using GeneDoc software v. 2.6.002 (Nicholas et al. 1997). Sequences were translated using the invertebrate mitochondrial code and cytochrome oxidase 2 protein (COII) and also checked 
for amino acid signatures. The new A. paggiae sequence was submitted to GenBank (accession number KF693769).

\section{RESULTS}

Anisakid specimens analyzed in this study were morphologically assigned to clade II and were identified as Anisakis paggiae according to the taxonomic key of Mattiucci et al. (2005). Measurements were taken and compared to those described in that study (Table 1). Morphological identification was based on 5 adult worms, viz. 3 females and 2 males (1 of which was used for light microscopy and the other for SEM). After light microscopy examination, posterior and anterior portions of 1 male and 1 female were deposited in CHIOC, as mentioned above. Three midsection fragments were used for molecular analyses.

\section{Morphological data}

Light microscopy revealed 3 lips at the anterior end, 2 ventrolateral and 1 dorsal, exhibiting a large
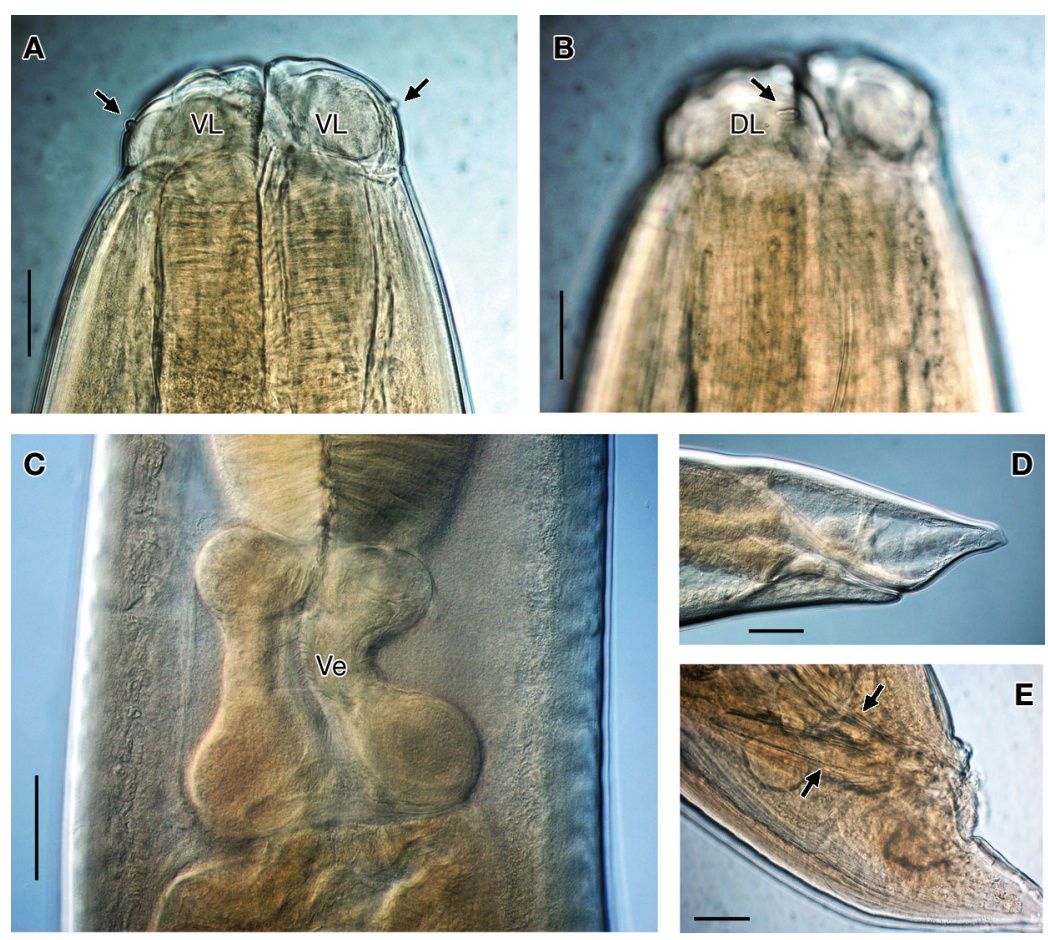

Fig. 1. Differential interference contrast images of Anisakis paggiae. (A) Anterior end showing papillae (arrows) in ventrolateral lips (VL). (B) Anterior end, showing large papilla (arrow) in the dorsal lip (DL). (C) Ventriculus (Ve) is short and violin-shaped. (D) Female conical tail with anal opening. (E) Posterior end of male with a pair of spicules (arrows) that are similar in size. Scale bars $=(A, B, E) 50 \mu m,(C, D) 100 \mu \mathrm{m}$

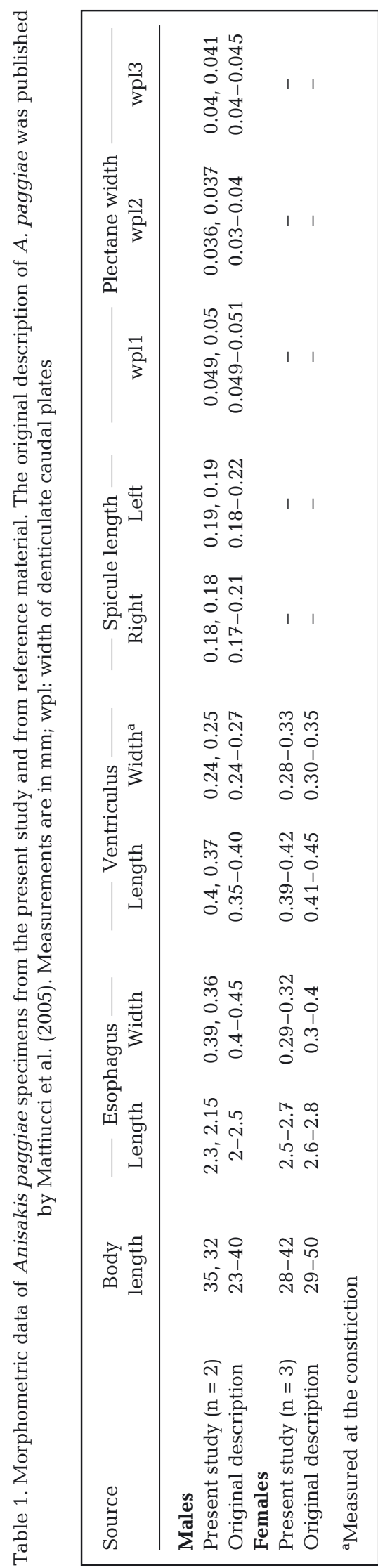


papilla (Fig. 1A,B). A short violin-shaped ventriculus could be observed (Fig. 1C, Table 1). The female posterior end exhibited a conical tail with a terminal anus (Fig. 1D), while males had a pair of similar spicules and numerous cloacal papillae (Fig. 1E, Table 1). SEM showed the anterior end with 3 prominent lips ornamented with denticles, amphids, and papillae (Fig. 2A). These papillae were present on the external surface of the lips (Fig. 2A). The internal
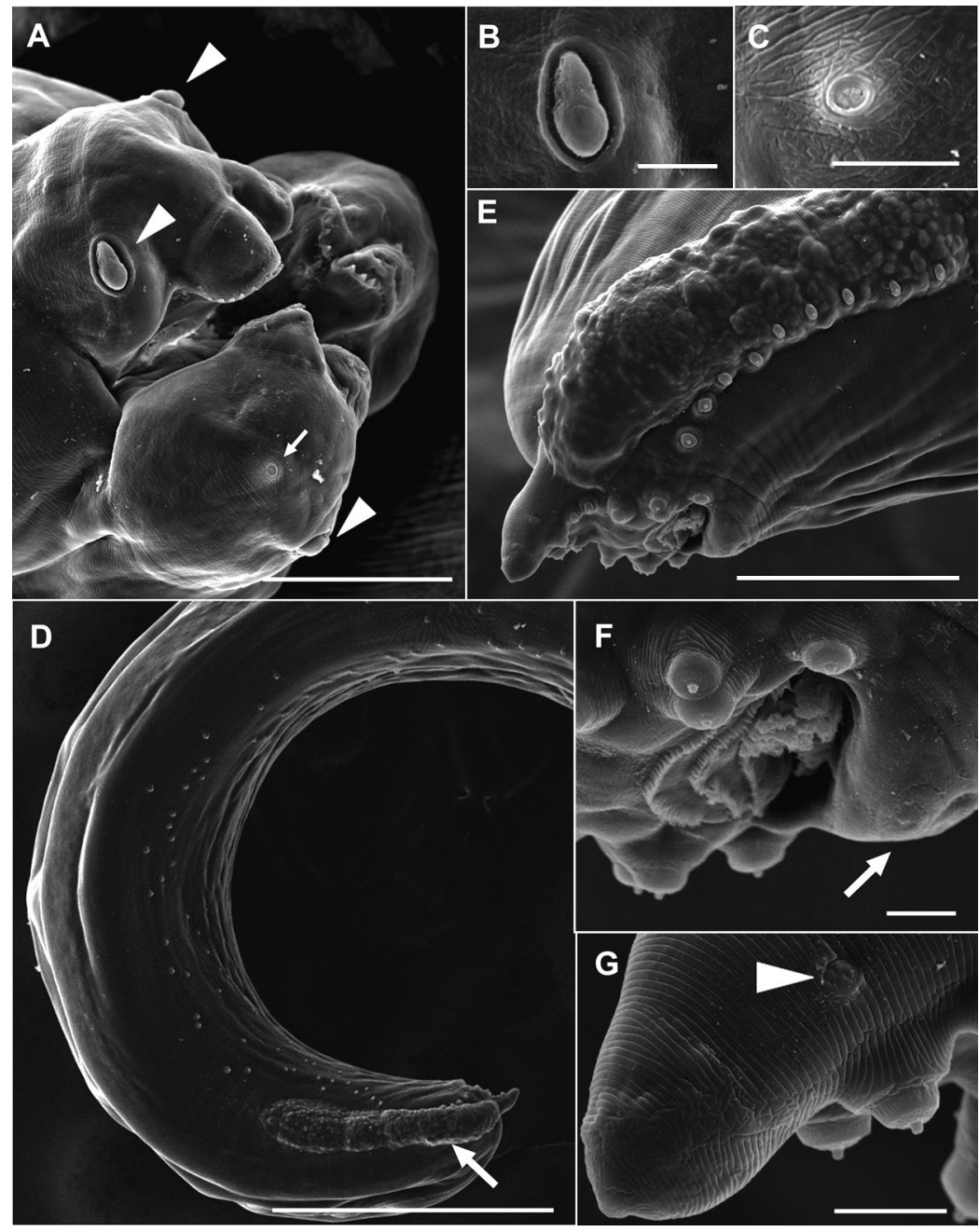

Fig. 2. Scanning electron microscopy of Anisakis paggiae male. (A) Anterior end, showing 1 dorsal lip with 2 large papillae (arrowheads) and 2 ventrolateral lips, 1 of which is showing 1 double papilla (arrowhead) and 1 amphid (arrow). (B) Detail of a large papilla. (C) Detail of an amphid. (D) Posterior end, showing numerous proximal papillae and 1 of the lateral cuticular dilatations (arrow). (E) Posterior end, showing 9 pairs of single precloacal papillae, a pair of single proximal papillae, a pair of double paracloacal papillae, and 4 pairs of single postcloacal papillae. (F) Detail of the cloacal region, showing the cuticular median structure (arrow), 3 denticulate caudal plates (plectanes), a pair of single proximal papillae, and a pair of double paracloacal papillae. (G) Rounded tail tip showing the last pair of postcloacal (distal) papillae and a phasmid (arrowhead). Scale bars = (A) $50 \mu \mathrm{m},(B, C, F, G) 10 \mu \mathrm{m}$, (D) $500 \mu \mathrm{m}$,

(E) $100 \mu \mathrm{m}$ surface presented cuticular bifid structures with internal denticles organized in plates (Fig. 2A). The dorsal lip presented 2 large papillae, and each ventrolateral lip had a double papilla and an amphid (Fig. 2A-C). At the posterior end, it was possible to observe a tail with a rounded terminal tip, a cuticular surface containing numerous caudal papillae, and 2 cuticular dilatation structures (Fig. 2D). Caudal papillae (nomenclature according to Fagerholm 1989) were as follows: 9 pairs of precloacal papillae were arranged in a single row, 1 pair of single proximal papillae, 1 pair of double paracloacal papillae, and 4 pairs of single postcloacal (distal) papillae (d1, d2, d3, and d4; Fig 2E,F). On the cloacal aperture, there were 3 denticulate caudal plates, wpl1, wpl2, wpl3 (plectanes; Fig. 2F). On the tip of the tail, on the lateral surface of the cuticle, we observed a pair of phasmids (Fig. 2G).

\section{Molecular data}

The nucleotide sequence of the cox 2 gene confirmed the species identity as A. paggiae in sample AV 60.6. Negative results were possibly due to poor quality/quantity of DNA, since specimen conservation was not appropriate for genetic analysis. BLASTn searches revealed $99 \%$ identity with A. paggiae (GenBank accession number DQ116434). Alignment with all previously characterized sequences of anisakid nematodes (505 bp), using an A. berlandi (formerly A. simplex sp. C; Mattiucci et al. 2014) sequence (DQ11 6429) as a reference, revealed 4 genetic signatures of clade II (i.e. polymorphisms shared only by individuals of clade II): G98A, A207T, G369A, and G477T, and 3 genetic signatures of $A$. paggiae species: G181T, G192T, and T396G (i.e. polymorphisms shared only by A. paggiae sequences; Fig. 3A). Pairwise interspecific analysis with 9 previously characterized Anisakis species and the Anisakis sp. sequence from this study revealed a high level of genetic identity with $A$. paggiae sequences $(\mathrm{K} 2 \mathrm{P}=0.023 ; \mathrm{SE}=0.004)$. In- 
traspecific genetic distances between available $A$. paggiae sequences and the one from this study ranged from $\mathrm{K} 2 \mathrm{P}=0.014(\mathrm{SE}=$ $0.005)$ to $\mathrm{K} 2 \mathrm{P}=0.033(\mathrm{SE}=0.008)$. The minimum value of the $A$. paggiae interspecific distance $(\mathrm{K} 2 \mathrm{P}=0.123 ; \mathrm{SE}=0.015)$ was obtained with $A$. ziphidarum. This value was higher than the maximum value of intraspecific distance of $A$. paggiae $(\mathrm{K} 2 \mathrm{P}=0.033$; $\mathrm{SE}$ $=0.008$ ), indicating the existence of the socalled barcode gap, i.e. a lack of overlap between intra- and interspecific distances (Ratnasingham \& Hebert 2007). Consequently, inclusion of the sequence reported here did not affect A. paggiae as a taxonomic unit. The generated $\mathrm{ML}$ and NJ topologies confirmed the identity of A. paggiae. Phylogenetic analysis revealed Anisakis sp. from this study clustering with all A. paggiae sequences reported in a monophyletic clade with a high bootstrap value $(\mathrm{ML}=94 \%, \mathrm{NJ}=100 \%$; Fig. 4). Comparison of the COII protein revealed a specific $A$. paggiae sequence with 168 amino acids from positions 24 to 191 using $A$. berlandi ( $A$. simplex C) DQ116429 sequence as a reference (Fig. 3B). The A. paggiae COII sequence is characterized by the genetic signatures G28V, N34S, V137I, and V169L, as well as $\mathrm{S} 33 \mathrm{~N}$, which is specific to clade II, and $\mathrm{A} 61 \mathrm{~F}$, which is specific to A. paggiae specimens (Fig. 3B).

\section{DISCUSSION}

Phylogenetic analysis based on allozymes and nuclear and mitochondrial DNA divided the genus Anisakis into 2 major clades. These clades were also distinguished by larval morphotype (Mattiucci \& Nascetti 2008, Mattiucci et al. 2009). The taxonomic key for adult recognition is based mainly on morphological features, including length and shape of both ventriculus and male spicules, as well as the arrangement of male caudal papillae. In this study, we identified Anisakis sp. specimens belonging to clade II based on the original description by Mattiucci et al. (2005). The morphologies of the ventricules and male spicules of these specimens were characteristic of species from clade II, viz. A. physeteris, A. brevispiculata,
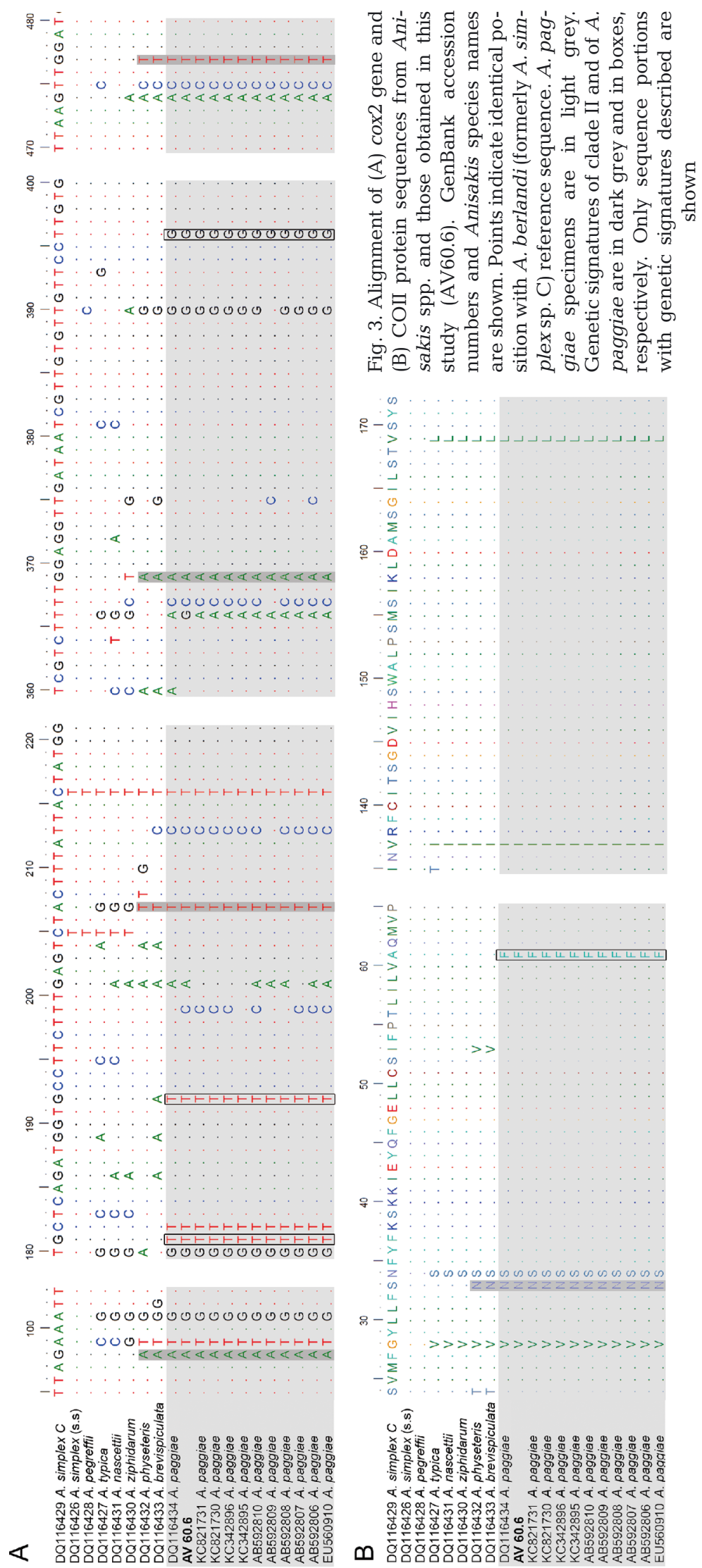


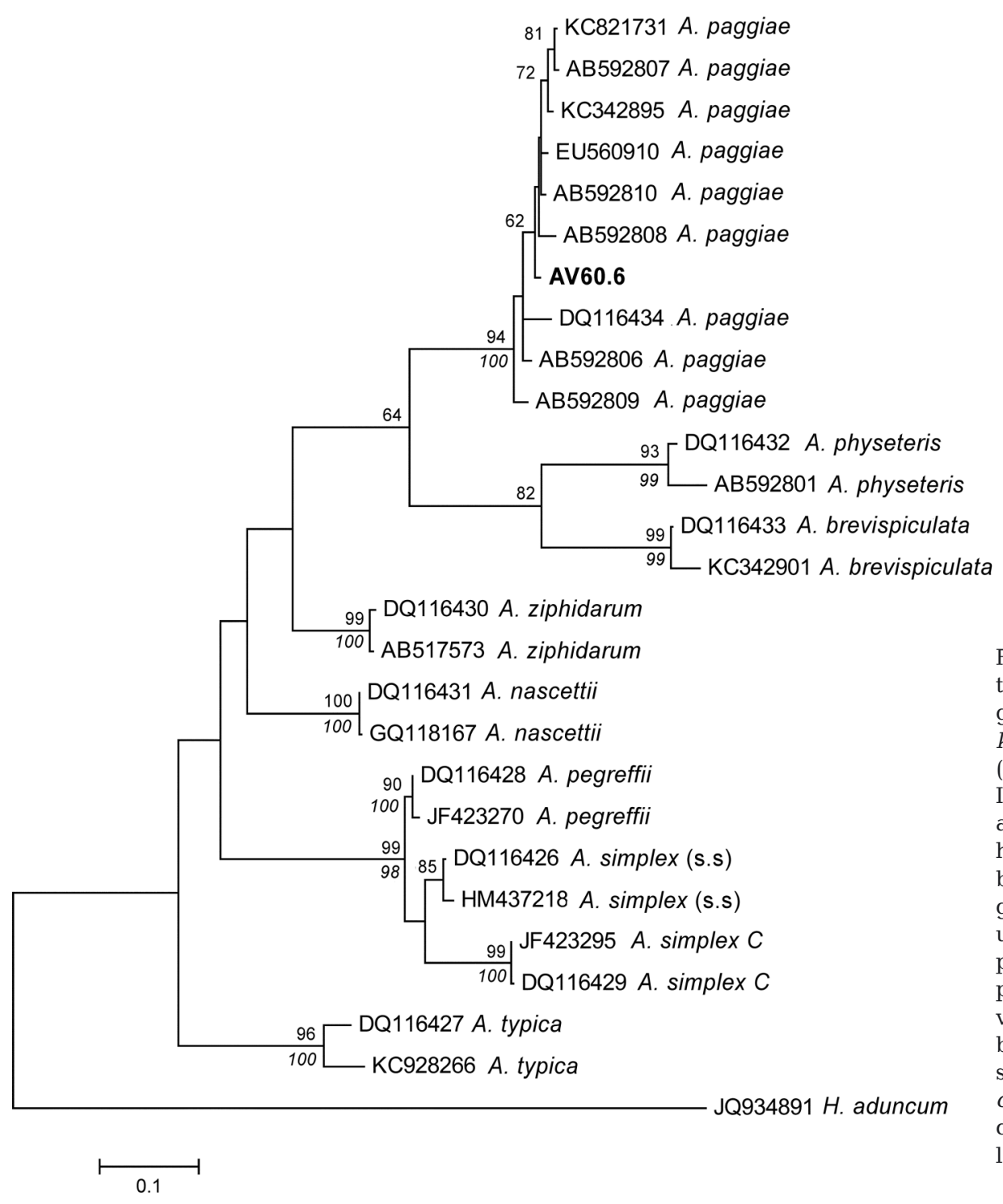

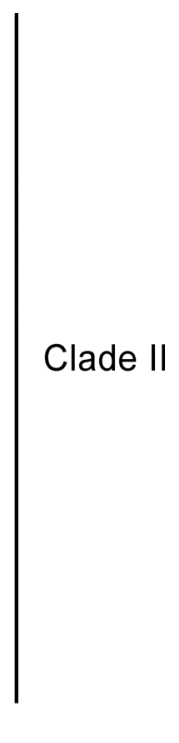

Fig. 4. Maximum likelihood (ML) tree inferred from mtDNA cox2 gene sequence data from Anisakis paggiae obtained in this study (AV60.6); the Anisakis spp. clade II cluster is also shown. Numbers at nodes are bootstrap values higher than $50 \%$. Regular numbers correspond to ML GTR plus gamma distribution support values and numbers in italics correspond to the neighbor-joining K2P plus gamma distribution support values. GenBank accession numbers and species names are shown. Hysterothylacium aduncum is the outgroup. The tree is drawn to scale, with branch lengths measured as the number of substitutions per site and A. paggiae. Spicules and ventricules of males were shorter than $0.35 \mathrm{~mm}$ and $0.56 \mathrm{~mm}$, respectively (Table 1), therefore excluding the possibility of specimens belonging to $A$. physeteris and $A$. brevispiculata (Mattiucci et al. 2005). As the spicules were shorter than $0.22 \mathrm{~mm}$ and 3 denticulate caudal plates were present, we determined that the species analyzed here was A. paggiae.

An adult male $A$. paggiae was analyzed by SEM. Our results showed that the anterior end of this nematode presented denticles that may be related to fixation on host tissue (Motta et al. 2008). The previously described double papillae in the dorsal lip (Mattiucci et al. 2005) did not have an external division, constituting, in fact, a large papilla. A similar structure was observed in Contracaecum osculatum by SEM (Fagerholm 1989). Moreover, the originally reported median papilla on the posterior end of males did not have the morphology of a papilla, being a cuticular median structure, as clearly shown by SEM analysis in the present study. Finally, the distribution of papillae in the cloacal region observed by SEM analysis resembled that reported by Mattiucci et al. (2005).

Morphological identification of $A$. paggiae was also confirmed genetically through cox 2 genetic distance comparison, NJ and MP phylogenetic trees, and in silico protein and DNA signature analyses. Inter- and intraspecific genetic distances supported our identification of A. paggiae. Phylogenetic trees exhibited a monophyletic and strongly supported clade with Brazilian Anisakis sp. and all previously character- 
Table 2. Hosts and geographical location of Anisakis paggiae described to date

\begin{tabular}{|lll|}
\hline Host(s) & Geographical location & Reference \\
\hline Definitive hosts & & Mattiucci et al. (2005) \\
Kogia breviceps and K. sima & Florida coast, USA & Valentini et al. (2006) \\
K. breviceps & West Atlantic Ocean (Florida coast) & Colón-Llavina et al. (2009) \\
K. breviceps and K. sima & Caribbean Sea & Cavallero et al. (2011) \\
K. breviceps and K. sima & Gulf of Mexico & Present study \\
K. sima & Atlantic coast of Brazil & Mattiucci et al. (2005) \\
Intermediate hosts & & Mattiucci et al. (2007) \\
Merluccius merluccius & Northeastern Atlantic Ocean (Galician coast) & Mattiucci et al. (2005) \\
Aphanopus carbo & Atlantic coast of Europe & Mattiucci et al. (2007) \\
Xiphias gladius & Central Atlantic waters (off Madeira) & Garcia et al. (2008) \\
& Atlantic coast of Europe & Garcia et al. (2011) \\
Theragra chalcogramma & Atlantic tropical-equatorial waters & Quiazon et al. (2009) \\
Beryx splendens & Eastern tropical and Central South Atlantic Ocean & Murata et al. (2011) \\
Anoplogaster cornuta & Pacific coast of Japan & Klimpel et al. (2011) \\
\hline
\end{tabular}

ized A. paggiae. DNA and protein signatures revealed not only polymorphisms specific to A. paggiae species, but also to clade II. Our study corroborates the usefulness of the $\operatorname{cox} 2$ genetic marker as a barcode of anisakid species, as previously shown (Valentini et al. 2006, Mattiucci et al. 2009, Knoff et al. 2012, Di Azevedo et al. 2014).

According to the literature (Table 2), the spectrum of definitive hosts of $A$. paggiae is limited to members of the family Kogiidae (Klimpel et al. 2008, 2010), including Kogia breviceps and K. sima. Regarding the intermediate/paratenic hosts of A. paggiae, some fish species have so far been recognized (Table 2). Cephalopods and marine fish, and occasionally crustaceans, are prey items for dwarf sperm whales (Willis \& Baird 1998, Culik 2010, Klimpel et al. 2010). Parasite transmission in aquatic ecosystems should be inferred in the context of food webs (Marcogliese 2002). Xiphias gladius, Beryx splenden, and Anoplogaster cornuta were reported as intermediary hosts of A. paggiae (Table 2) and are found in Brazilian waters (Froese \& Pauly 2014). Therefore, it would be expected that $A$. paggiae could be found in the littoral of this country. Moreover, according to Culik (2010), the geographical distribution of dwarf sperm whales is widespread in tropical and temperate seas, including South Atlantic waters. The abovementioned arguments suggest a possible maintenance of the $A$. paggiae cycle in this region.

Until recently, reports of $A$. paggiae had been limited to boreal waters (Table 2). A record of A. paggiae infecting $K$. breviceps along the South African coast, reported by Mattiucci \& Nascetti $(2006,2008)$, is not supported by those studies' referred literature. Therefore, the geographic distribution of $A$. paggiae had been restricted to a range of 15 to $45^{\circ} \mathrm{N}$, before it expanded to $10^{\circ} \mathrm{S}$ with findings in Atlantic tropicalequatorial waters (Garcia et al. 2011). Our data revealed the presence of $A$. paggiae in a new geographical location, i.e. the northeast coast of Brazil, Atlantic coast of South America, suggesting a wider distribution of this species and confirming its austral occurrence.

Acknowledgements. We are grateful to AQUASIS's Projeto Manati, sponsored by Petrobras through its Petrobras Socioambiental Program, for providing the specimens. We thank Dr. Áurea Maria Lage de Moraes, from the Laboratório de Bioquímica e Bioprospecção de Fungos, IOC/FIOCRUZ, for allowing the use of Olympus BX41 microscope to obtain the photographic records, and CENABIO III (Microscopy Division) for SEM support. We thank Dr. Adriana Cabral (Fundação Tecnico-Educacional Souza Marques) for the English revision. This study was supported by Coordenação de Aperfeiçoamento de Pessoal de Nível Superior (CAPES; grant number 032/2010). We are grateful to the Conselho Nacional de Desenvolvimento Científico e Tecnológico (CNPq) for the scholarship to A.M.I. (grant number 300484/2008-9) and to CAPES for the scholarship to M.I.N.D.A. (grant number 032/2010).

\section{LITERATURE CITED}

Borges JN, Cunha LF, Santos HL, Monteiro-Neto C, Portes Santos C (2012) Morphological and molecular diagnosis of anisakid nematode larvae from cutlassfish (Trichiurus lepturus) off the coast of Rio de Janeiro, Brazil. PLoS ONE 7:e40447 
Carvalho VL, Bevilaqua CM, Iñiguez AM, Mathews-Cascon $\mathrm{H}$ and others (2010) Metazoan parasites of cetaceans off the northeastern coast of Brazil. Vet Parasitol 173: $116-122$

> Cavallero S, Nadler SA, Paggi L, Barros NB, D'Amelio S (2011) Molecular characterization and phylogeny of anisakid nematodes from cetaceans from southeastern Atlantic coasts of USA, Gulf of Mexico, and Caribbean Sea. Parasitol Res 108:781-792

> Colón-Llavina MM, Mignucci-Giannoni AA, Mattiucci S, Paoletti M, Nascetti G, Williams EH Jr (2009) Additional records of metazoan parasites from Caribbean marine mammals, including genetically identified anisakid nematodes. Parasitol Res 105:1239-1252

Culik BM (2010) Odontocetes - the toothed whales. Distribution, behaviour, migration and threats. UNEP/CMS Secretariat, Bonn

> D'Amelio S, Mathiopoulos KD, Santos CP, Pugachev ON, Webb SC, Picanço M, Paggi L (2000) Genetic markers in ribosomal DNA for the identification of members of the genus Anisakis (Nematoda: Ascaridoidea) defined by polymerase-chain-reaction-based restriction fragment length polymorphism. Int J Parasitol 30:223-226

- Davey JT (1971) A revision of the Genus Anisakis Dujardin, 1845 (Nematoda: Ascaridata). J Helminthol 45:51-72

> Di Azevedo MIN, Carvalho VL, Iñiguez AM (2014) First record of the anisakid nematode Anisakis nascettii in the Gervais' beaked whale Mesoplodon europaeus from Brazil. J Helminthol (in press) doi:10.1017/S0022149X14000765

Fagerholm HP (1989) Intra-specific variability of the morphology in a single population of the seal parasite Contracaecum osculatum (Rudolphi) (Nematoda, Ascaridoidea), with a redescription of the species. Zool Scr 18: $33-41$

Froese F, Pauly D (2014) FishBase. www.fishbase.org (accessed 29 Mar 2014)

> Garcia A, Santos MN, Damiano S, Nascetti G, Mattiucci S (2008) The metazoan parasites of swordfish from Atlantic tropical-equatorial waters. J Fish Biol 73:2274-2287

Garcia A, Mattiucci S, Damiano S, Santos MN, Nascetti G (2011) Metazoan parasites of swordfish, Xiphias gladius (Pisces: Xiphiidae) from the Atlantic Ocean: implications for host stock identification. J Mar Sci 68:175-182

Iñiguez AM, Santos CP, Vicente AC (2009) Genetic characterization of Anisakis typica and Anisakis physeteris from marine mammals and fish from the Atlantic Ocean off Brazil. Vet Parasitol 165:350-356

Iñiguez AM, Carvalho VL, Alves Motta MR, Sousa Nunes Pinheiro DC, Paulo Vicente AC (2011) Genetic analysis of Anisakis typica (Nematoda: Anisakidae) from cetaceans of the northeast coast of Brazil: new data on its definitive hosts. Vet Parasitol 178:293-299

Iñiguez AM, Leles D, Jaeger LH, Carvalho-Costa FA, Araújo A (2012) Genetic characterization and molecular epidemiology of Ascaris spp. from humans and pigs in Brazil. Trans R Soc Trop Med Hyg 106:604-612

> Kimura M (1980) A simple method for estimating evolutionary rates of base substitutions through comparative studies of nucleotide sequences. J Mol Evol 16:111-120

> Klimpel S, Kellermanns E, Palm HW (2008) The role of pelagic swarm fish (Myctophidae: Teleostei) in the oceanic life cycle of Anisakis sibling species at the MidAtlantic Ridge. Parasitol Res 104:43-53

Klimpel S, Busch MW, Kuhn T, Rohde A, Palm HW (2010)
The Anisakis simplex complex off the South Shetland Islands (Antarctica): endemic populations versus introduction through migratory hosts. Mar Ecol Prog Ser 403:1-11

> Klimpel S, Kuhn T, Busch MW, Karl H, Palm HW (2011) Deep-water life cycle of Anisakis paggiae (Nematoda: Anisakidae) in the Irminger Sea indicates kogiid whale distribution in north Atlantic waters. Polar Biol 34: 899-906

Knoff M, Felizardo NN, Iñiguez AM, Maldonado A Jr, Lopes Torres EJ, Pinto RM, Gomes DC (2012) Genetic and morphological characterization of a new species of the genus Hysterothylacium (Nematoda) from Paralichthys isosceles Jordan, 1890 (Pisces: Teleostei) of the Neotropical Region, state of Rio de Janeiro, Brazil. Mem Inst Oswaldo Cruz 107:186-193

Lopes Torres EJ, De Souza W, Miranda K (2013) Comparative analysis of Trichuris muris surface using conventional, low vacuum, environmental and field emission scanning electron microscopy. Vet Parasitol 196: 409-416

Luque JL, Muniz-Pereira LC, Siciliano S, Siqueira LR, Oliveira MS, Vieira FM (2010) Checklist of helminth parasites of cetaceans of Brazil. Zootaxa 2548:57-68

Marcogliese DJ (2002) Food webs and the transmission of parasites to marine fish. Parasitology 124:83-99

Mattiucci S, Nascetti G (2006) Molecular systematics, phylogeny and ecology of anisakid nematodes of the genus Anisakis Dujardin, 1845: an update. Parasite 13:99-113

Mattiucci S, Nascetti G (2008) Advances and trends in the molecular systematics of anisakid nematodes, with implications for their evolutionary ecology and host-parasite co-evolutionary processes. Adv Parasitol 66:47-148

> Mattiucci S, Paggi L, Nascetti G, Portes Santos C and others (2002) Genetic markers in the study of Anisakis typica (Diesing, 1860): larval identification and genetic relationships with other species of Anisakis Dujardin, 1845 (Nematoda: Anisakidae). Syst Parasitol 51:159-170

> Mattiucci S, Nascetti G, Dailey M, Webb SC, Barros NB, Cianchi R, Bullini L (2005) Evidence for a new species of Anisakis Dujardin, 1845: morphological description and genetic relationships between congeners (Nematoda: Anisakidae). Syst Parasitol 61:157-171

> Mattiucci S, Abaunza P, Damiano S, Garcia A, Santos MN, Nascetti G (2007) Distribution of Anisakis larvae, identified by genetic markers, and their use for stock characterization of demersal and pelagic fish from European waters: an update. J Helminthol 81:117-127

> Mattiucci S, Paoletti M, Webb SC (2009) Anisakis nascettii n. sp. (Nematoda: Anisakidae) from beaked whales of the southern hemisphere: morphological description, genetic relationships between congeners and ecological data. Syst Parasitol 74:199-217

> Mattiucci S, Cipriani P, Webb SC, Paoletti M and others (2014) Genetic and morphological approaches distinguish the three sibling species of the Anisakis simplex species complex, with a species designation as Anisakis berlandi n. sp. for A. simplex sp. C (Nematoda: Anisakidae). J Parasitol 100:199-214

Motta MR, Pinheiro DC, Carvalho VL, Viana DA, Paulo Vicente AC, Iñiguez AM (2008) Gastric lesions associated with the presence of Anisakis spp. Dujardin, 1845 (Nematoda: Anisakidae) in cetaceans stranded on the coast of Ceara, Brazil. Biota Neotrop 8:91-95

> Murata R, Suzuki J, Sadamasu K, Kai A (2011) Morphological and molecular characterization of Anisakis larvae 
(Nematoda: Anisakidae) in Beryx splendens from Japanese waters. Parasitol Int 60:193-198

Nadler SA, Hudspeth DS (2000) Phylogeny of the Ascaridoidea (Nematoda: Ascaridida) based on three genes and morphology: hypotheses of structural and sequence evolution. J Parasitol 86:380-393

Nicholas KB, Nicholas HB Jr, Deerfield DW II (1997) GeneDoc: analysis and visualization of genetic variation. EMB net.News 4:1-4. http://journal.embnet.org/index.php/ embnetnews/article/viewFile/115/140

Quiazon KM, Yoshinaga T, Santos MD, Ogawa K (2009) Identification of larval Anisakis spp. (Nematoda: Anisakidae) in Alaska pollock (Theragra chalcogramma) in northern Japan using morphological and molecular markers. J Parasitol 95:1227-1232

Quiazon KM, Santos MD, Yoshinaga T (2013) Anisakis species (Nematoda: Anisakidae) of dwarf sperm whale Kogia

Editorial responsibility: Sven Klimpel,

Frankfurt, Germany sima (Owen, 1866) stranded off the Pacific coast of southern Philippine archipelago. Vet Parasitol 197:221-230

Ratnasingham S, Hebert PDN (2007) BOLD: The Barcode of Life Data System (www.barcodinglife.org). Mol Ecol Notes 7:355-364

Tamura K, Stecher G, Peterson D, Filipski A, Kumar S (2013) MEGA 6: Molecular Evolutionary Genetics Analysis version 6.0. Mol Biol Evol 30:2725-2729

Valentini A, Mattiucci S, Bondanelli P, Webb SC, MignucciGiannone AA, Colom-Llavina MM, Nascetti G (2006) Genetic relationships among Anisakis species (Nematoda: Anisakidae) inferred from mitochondrial cox2 sequences, and comparison with allozyme data. J Parasitol 92:156-166

Willis PM, Baird RW (1998) Status of the dwarf sperm whale (Kogia simus) in Canada. Can Field-Nat 112: 114-125

Submitted: June 16, 2014; Accepted: November 18, 2014

Proofs received from author(s): February 27, 2015 